\title{
Additive nature of distension and surfactant perturbation on alveolocapillary permeability
}

\author{
J. John*, V. Taskar*, E. Evander*, P. Wollmer**, B. Jonson*
}

\begin{abstract}
Additive nature of distension and surfactant perturbation on alveolocapillary permeability. J. John, V. Taskar, E. Evander, P. Wollmer, B. Jonson. @ ERS Journals Ltd 1997.

ABSTRACT: The aim of this study was to determine whether the effects of alveolar distention and surfactant dysfunction on alveolocapillary barrier function are different and additive.

Pulmonary clearance of aerosolized technetium-99m-labelled human serum albumin (99mTc-HSA) was used to characterize barrier function after perturbing the surfactant system with the detergent dioctyl sodium sulphosuccinate either singly or in combination with large tidal volume ventilation (LTVV). Clearance was measured for $3 \mathrm{~h}$ (Experimental ventilation) in four groups ( $\mathrm{n}=6 \mathrm{each}$ ) of rabbits: 1) Controls; 2) Detergent; 3) LTVV; and 4) Detergent+LTVV. Restoration of clearance (Recovery) was studied for $3 \mathrm{~h}$ under conventional ventilation.

The half-life of clearance $(t 1 / 2)$ decreased during LTVV (305 min) compared to $1,055 \mathrm{~min}$ in Controls. Detergent induced a biexponential clearance with slow $(t 1 / 2 S)$ and fast $(t 1 / 2 \mathrm{~F})$ half-lives of 670 and $15.4 \mathrm{~min}$, respectively. The fast fraction (fF) was 0.20. Clearance in the Detergent+LTVV group was also biexponential. The $t 1 / 2 \mathrm{~F}$ and fF were similar to the Detergent group. The $t 1 / 2 \mathrm{~S}$ was similar to the LTVV group. The $f F$ in this group increased to 0.36 during Recovery $(p<0.01$ versus Detergent group and $\mathrm{p}<0.05$ versus Experimental ventilation).

The diverse kinetics of clearance during large tidal volume ventilation and surfactant dysfunction suggest the presence of different mechanisms affecting the barrier. The mechanisms have additive characteristics, which superimpose to produce lung injury.

Eur Respir J., 1997; 10: 192-199.
\end{abstract}

\author{
*Dept of Clinical Physiology, University \\ Hospital of Lund, Lund, Sweden. **Dept \\ of Clinical Physiology, Malmö General Hos- \\ pital, Malmö, Sweden. \\ Correspondence: B. Jonson \\ Department of Clinical Physiology \\ University Hospital of Lund \\ S-221 85 Lund \\ Sweden
}

Keywords: Alveolocapillary membrane lung injury

pulmonary surfactants

tidal volume

Received: May 101995

Accepted after revision August 211996

This study was supported by the Swedish Medical Research Council (grants 02872, 04732 and 10841), the Swedish Heart Lung Foundation and the Medical Faculty of Lund.
The alveolocapillary membrane functions as a barrier to limit the transfer of molecules from the alveolus into the blood $[1,2]$. The continuous alveolar epithelial lining, comprised predominantly of type 1 pneumocytes, is the principal determinant of the integrity of the alveolocapillary barrier [2, 3]. Studies with radiolabelled tracers administered in aerosol form have indicated an important role for the surfactant system as a barrier against the transfer of hydrophilic solutes $[4,5]$. The permeability of the alveolocapillary barrier can be assessed by measuring the pulmonary clearance of aerosolized technetium-99m-labelled diethylene triamine penta-acetate (99mTc-DTPA; molecular weight $492 \mathrm{Da}$ ). Increased clearance occurs in surfactant deficiency as in preterm lambs [6], after lung lavage [7], or in detergent treated lungs $[8,9]$. Replenishment of surfactant [7] and an experimentally increased alveolar surfactant content [10] retard the clearance rate of $99 \mathrm{~m}$ Tc-DTPA. The barrier has been further characterized by a marked increase in permeability to ${ }^{99 \mathrm{~m} T c-D T P A}$ when surfactant is perturbed by small doses of the detergent dioctyl sodium sulphosuccinate [9]. The increased permeability is characterized by the formation of two distinct and nonexchanging pools or compartments of $99 \mathrm{mTc}-\mathrm{DTPA}$. The mechanism by which detergent affects surfactant to form two pools of tracer remains unknown.

Ventilation patterns are known to affect the clearance of radiotracers from the lungs [11-15]. An increase in lung volume, mediated, e.g. by positive end-expiratory pressure (PEEP) or ventilation with large tidal volumes, accelerates the clearance. The effect has been attributed to stretching of intercellular junctions, an increase in surface area and surfactant dysfunction.

Recently, we have studied the combined effects of large tidal volume ventilation (LTVV) and detergentinduced surfactant dysfunction on clearance of $99 \mathrm{mTc}-$ DTPA in rabbits [16]. It was concluded that the mechanisms increasing the permeability of the alveolocapillary barrier appear to be different and additive.

The aim of this study was to further characterize the alveolocapillary barrier function by studying clearance kinetics of a larger tracer molecule, such as technetium-99m-labelled human serum albumin (99mTc-HSA; molecular weight $69,000 \mathrm{Da}$ ). The same insults to the alveolocapillary barrier were applied as in the preceding study namely increased alveolar volume achieved by large tidal volume ventilation and surfactant dysfunction by $2 \%$ detergent. The study of clearance kinetics 
of albumin during and after insults, such as detergent or/and LTVV, may help in distinguishing whether distinct and different mechanisms govern an increased clearance and if the mechanisms are additive.

\section{Methods}

\section{Animals}

The study involved a total of 30 rabbits weighing $2.9 \pm 0.3 \mathrm{~kg}$. Twenty four rabbits were studied according to Protocol A (see below) and divided into four groups ( $\mathrm{n}=6$ each) as follows: 1) Control group (vehicle aerosol and conventional ventilation); 2) Detergent group (detergent aerosol and conventional ventilation; 3) LTVV group (vehicle aerosol and large tidal volume ventilation; and 4) Detergent+LTVV group (detergent aerosol and large tidal volume ventilation). Three rabbits each were studied according to Protocols B and C.

\section{Study design}

Protocol A (fig. 1) comprised three periods: Baseline period; Experimental ventilation; and Recovery period. The animals were prepared during the Baseline period of approximately $1 \mathrm{~h}$, at the end of which they were in steady state. After an alveolar recruitment procedure (see below), the arterial blood gas values and lung mechanics in the Baseline period were recorded. Either detergent or vehicle aerosol was then randomly administered ( $\mathrm{n}=12$ each), immediately followed by an aerosol of $99 \mathrm{mTc}-\mathrm{HSA}$. Clearance was measured during $3 \mathrm{~h}$ of Experimental ventilation (either conventional ventilation or LTVV). Experimental ventilation was interrupted at $90 \mathrm{~min}$ to repeat the detergent or vehicle aerosol. At the end of Experimental ventilation the recruitment procedure, lung mechanics and arterial blood gas determination were repeated. An aerosol of $99 \mathrm{~m}$ Tc-HSA was readministered just before $3 \mathrm{~h}$ Recovery period, and clearance was measured in all animals under conventional ventilation. After the Recovery period, lung mec- hanics and arterial blood gas determination were repeated after a recruitment procedure and the animals were then sacrificed. Accordingly, the dependent variables were clearance and lung mechanics. The independent variables were the ventilating volume and the integrity of the surfactant system.

The duration of action of $2 \%$ detergent was studied in three animals. ${ }^{99 \mathrm{~m} T \mathrm{~T}-H S A}$ was administered $60 \mathrm{~min}$ after detergent (Protocol B).

The effect of administering detergent 90 min after $99 \mathrm{mTc}-\mathrm{HSA}$ was studied in another three animals under conventional ventilation by interrupting Experimental ventilation at $90 \mathrm{~min}$ to deliver detergent for the first time (Protocol C).

\section{Animal preparation}

Anaesthesia was induced with an intravenous bolus of pentothal sodium, $17.5 \mathrm{mg} \cdot \mathrm{kg}^{-1}$, and was maintained at $1.25 \mathrm{mg} \cdot \mathrm{kg}^{-1} \cdot \mathrm{min}^{-1}$. A tracheostomy was performed and animals were ventilated in the pressure control mode of the Servo Ventilator 900C (Siemens-Elema AB, Solna, Sweden) by setting inspiratory airway pressure $(P \mathrm{I})$ so that tidal volume $(V \mathrm{~T})$ was $13 \mathrm{~mL} \cdot \mathrm{kg}^{-1}$ at a respiratory frequency of 40 breaths $\cdot \mathrm{min}^{-1}$, denoted conventional ventilation. A neuromuscular block during ventilation was maintained with $0.03 \mathrm{mg} \cdot \mathrm{kg}^{-1}$ of pancuronium bromide, administered intravenously half hourly. Blood gas levels were measured using conventional electrodes (ABL 300; Radiometer A/S, Copenhagen, Denmark).

\section{Aerosol administration and tracer stability}

Two percent detergent (Sigma, St Louis, MO, USA) or its vehicle $(50 \%$ ethanol in normal saline) was aerosolized over 200 breaths [9] using an UltraVent nebulizer (Mallinckrodt Diagnostica, Petten, The Netherlands). 99mTc-HSA (Mallinckrodt Diagnostica, The Netherlands) was aerosolized until a count rate of 500 counts $\cdot \mathrm{s}^{-1}$ was attained over the thorax. The mass median aerodynamic diameter of the primary droplet, as measured $1 \mathrm{~cm}$ from the endotracheal tube by a laser light scattering technique, was $1.7 \mu \mathrm{m}$. The amount of liquid deposited in

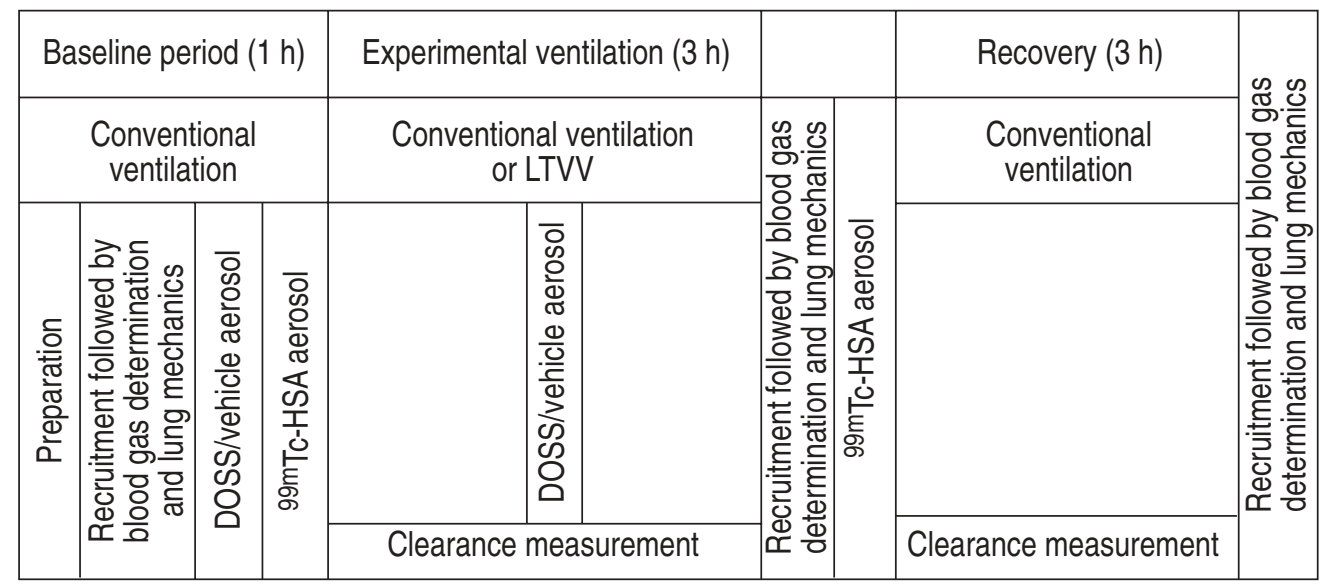

Fig. 1. - Protocol A of the study design. LTVV: large tidal volume ventilation; DOSS dioctyl sodium sulphosuccinate (detergent); ${ }^{99 m T c-H S A: ~}$ technetium-99m-labelled human serum albumin. 
the pulmonary parenchyma was approximately $10 \mu \mathrm{L}$. Thin layer chromatography of the albumin preparation using acetone showed tracer binding to be $>99 \%$ and unaffected by nebulization. Chromatography was also performed 1, 3 and $6 \mathrm{~h}$ after mixing aliquots of $99 \mathrm{mTc}-$ HSA with detergent in a 1:1 ratio and in blood samples from the animals. Free $99 \mathrm{mTc}$ was $<1 \%$, ensuring that detergent did not interfere with the binding of $99 \mathrm{mTc}$ to HSA. Binding was $>96 \%$ in plasma obtained during Experimental ventilation and Recovery.

\section{Experimental ventilation}

Conventional ventilation was continued as initiated in the Baseline period. LTVV was given in the pressure control mode with $P$ I of $25 \mathrm{cmH}_{2} \mathrm{O}$ over PEEP and frequency of 20 breaths $\mathrm{min}^{-1}$. PEEP was $2 \mathrm{cmH}_{2} \mathrm{O}$ and inspiratory to expiratory (I:E) ratio $1: 2$ during either mode of ventilation. During ventilation, animals were monitored, including determination of arterial blood gas values, end-tidal partial pressure of $\mathrm{CO}_{2}$ from the $\mathrm{CO}_{2}$ analyser (930; Siemens-Elema, Sweden) and parameters of lung mechanics.

\section{Lung mechanics}

To standardize conditions and eliminate the effect of temporary atelectasis, an airway distending pressure of $20 \mathrm{cmH}_{2} \mathrm{O}$ was applied for $15 \mathrm{~s}$ as a "recruitment procedure". Pressure at airway opening was measured using a pressure transducer (Sensym SX01DN, Germany), and flow signals were recorded with a pneumotachograph (Fleisch 000) attached to a Sensym pressure transducer. The signals were stored in a personal computer and the pressure-volume $(\mathrm{P} / \mathrm{V})$ loop during each period was plotted using a commercial software package (Microsoft Excel 4.0). The dynamic compliance of the respiratory system ( $C$ dyn $)$ was derived as:

$$
C \text { dyn }=V \mathrm{~T} \cdot(P \text { pause-PEEP })^{-1} \cdot \text { weight }^{-1}
$$

where $P$ pause was the pressure at airway opening at the end of inspiration.

\section{Measurement of ${ }^{99 m}$ Tc-HSA clearance}

Radioactivity was measured [9] in the anterior view, for $3 \mathrm{~h}$ each during the Experimental and Recovery periods, with a gamma camera (Portacamera; General Electric, WI, USA) equipped with a converging collimator and connected to a computer (Gamma 11; Digital Equipment, MA, USA). All images were recorded in $64 \times 64$ pixels. The time activity curve over the region of interest corresponding to the lungs was corrected for physical decay. An intravenous injection of $3 \mathrm{MBq}$ of 99mTc-HSA was given $15 \mathrm{~min}$ from the end of the Recovery period to enable correction for recirculating tracer in the blood [17]. Mono- or biexponential equations were fitted to the curves by minimization of the sum of squares using the Nelder-Mead simplex method [18]. Monoexponential clearance was expressed as:

$$
\mathrm{A}(t)=\mathrm{A}(0) \cdot \mathrm{e}^{-\mathrm{k} t}
$$

where $\mathrm{A}(t)$ and $\mathrm{A}(0)$ are the radioactivity over the region of interest at time $t$ and time zero, respectively, while $\mathrm{k}$ is the rate constant. Clearance was expressed as the half-life $\left(t 1 / 2=\ln 2 \cdot \mathrm{k}^{-1}\right)$. The biexponential fit was described as:

$$
\mathrm{A}(t)=\mathrm{fF} \cdot \mathrm{A}(0) \cdot \mathrm{e}^{-\mathrm{kF} t}+(1-\mathrm{fF}) \cdot \mathrm{A}(0) \cdot \mathrm{e}^{-\mathrm{ks} t}
$$

$\mathrm{fF}$ is the fraction of tracer initially deposited in the rapidly clearing pool and $\mathrm{kF}$ and $\mathrm{kS}$ are the rate constants of clearance from the fast and slow pools, respectively. In groups where clearance is described by bicompartmental kinetics during the Experimental period, the activity in the fast pool will be minimal at the end of $3 \mathrm{~h}$ depending on $\mathrm{kF}$. The second dose of radioactivity will then be added on to the residual activity from the first deposition, which is now predominantly in the slow compartment. If clearance during the Recovery period is still bicompartmental, the total time activity curve will underestimate fF because of the activity from the first deposition that is retained in the slow compartment. Therefore, in those animals, the time activity curve from the Experimental period was extrapolated into the Recovery period and subtracted from the total activity curve to generate clearance curves for the Recovery period.

Equation (3) is valid in a stable model. The effect of detergent on pulmonary clearance of $99 \mathrm{~m}$ Tc-DTPA was shown to be reversible [9]. The instability could be described as a return of the fast fraction to the slower pool occurring at a rate described by a half-life of the fast pool, denoted kFS. The equation taking kFS into consideration would be:

$$
\mathrm{A}(t)=\mathrm{A}(0) \frac{(\mathrm{kF}-\mathrm{kS}) \mathrm{fF}}{\mathrm{kF}+\mathrm{kFS}-\mathrm{kS}} \mathrm{e}^{-\left(\mathrm{kF}_{\mathrm{F}}+\mathrm{kFS}_{\mathrm{F}}\right) t}+\mathrm{A}(0)\left(1-\mathrm{fF}+\frac{\mathrm{kFS} \cdot \mathrm{fF}}{\mathrm{kF}+\mathrm{kFS}-\mathrm{kS}}\right) \mathrm{e}^{-\mathrm{kst}}(4)
$$

kFS was determined as described previously [9] in three rabbits which were administered ${ }^{99 \mathrm{~m} T c-H S A} 60$ min after detergent administration (Protocol B). Clearance was expressed as the half-life of the fast $\left(t 1 / 2 \mathrm{~F}=\ln 2 \cdot \mathrm{kF}^{-1}\right)$ and slow $\left(t 1 / 2 \mathrm{~S}=\ln 2 \cdot \mathrm{kS}^{-1}\right)$ compartments, while $t 1 / 2 \mathrm{FS}$ was $\ln 2 \cdot \mathrm{kFS}^{-1}$.

\section{Data analysis}

Data were analysed using the software package Statistical Package for the Social Sciences (SPSS) for Windows. All values are expressed as mean \pm SD. Intergroup comparisons were made using the analysis of variance (ANOVA) with the Bonferroni correction. Sequential measurements within the same group were compared with the paired t-test. The mono- and biexponential curve fits were compared with an F-test, to detect whether the biexponential model was required to describe the data. A p-value of less than 0.05 was considered significant. 


\section{Results}

\section{Blood gases and lung mechanics}

Vital parameters in each animal were stable throughout the experiment. Baseline partial pressure of oxygen in arterial blood $\left(\mathrm{Pa}_{\mathrm{a}} \mathrm{O}_{2}\right)$ was similar in the four groups (table 1). $\mathrm{Pa}, \mathrm{O}_{2}$ declined in the Detergent+LTVV group after Experimental ventilation $(\mathrm{p}<0.05)$. It improved during Recovery but was still lower than that in the other groups. Partial pressure of carbon dioxide in arterial blood $\left(\mathrm{Pa}, \mathrm{CO}_{2}\right)$ remained stable in all groups.

Baseline P/V curves (fig. 2) and $C$ dyn (table 1) were similar in the four groups. The $\mathrm{P} / \mathrm{V}$ curves in the Control and Detergent groups were similar during Experimental ventilation and Recovery. Tidal volume during Experimental ventilation was $35.5 \pm 2.2 \mathrm{~mL}$ in Controls, $87.0 \pm 7.3$ $\mathrm{mL}$ in the LTVV group, $34.0 \pm 1.7 \mathrm{~mL}$ in the Detergent group, and $68.5 \pm 8.3 \mathrm{~mL}$ in the Detergent+LTVV group. At the end of Experimental ventilation, $C$ dyn had increased in the LTVV group $(\mathrm{p}<0.001)$. $C$ dyn in the Detergent+ LTVV group was lower after Experimental ventilation $(p<0.05)$ but partially improved towards the end of the Recovery period.

At necropsy, all animals in the Detergent+LTVV group had foam in the trachea and on the cut lung surface and large areas of atelectasis, especially in the lower lobes. These findings were not present in the other three groups.

Table 1. - Arterial blood gas tensions and dynamic compliance at Baseline, after $3 \mathrm{~h}$ Experimental ventilation and after Recovery ( $n=6$ in each group)

\begin{tabular}{|c|c|c|c|c|c|c|c|c|c|}
\hline & \multicolumn{3}{|c|}{$P_{\mathrm{a}, \mathrm{O}_{2}} \mathrm{kPa}$} & \multicolumn{3}{|c|}{$P \mathrm{a}_{1} \mathrm{CO}_{2} \mathrm{kPa}$} & \multicolumn{3}{|c|}{$C_{\text {dyn }} \mathrm{ml} \cdot \mathrm{cmH}_{2} \mathrm{O}^{-1} \cdot \mathrm{kg}^{-1}$} \\
\hline & Baseline & $\begin{array}{c}\text { After } \\
\text { Experimental } \\
\text { ventilation }\end{array}$ & $\begin{array}{c}\text { After } \\
\text { Recovery }\end{array}$ & Baseline & $\begin{array}{c}\text { After } \\
\text { Experimental } \\
\text { ventilation }\end{array}$ & $\begin{array}{c}\text { After } \\
\text { Recovery }\end{array}$ & Baseline & $\begin{array}{c}\text { After } \\
\text { Experimental } \\
\text { ventilation }\end{array}$ & $\begin{array}{c}\text { After } \\
\text { Recovery }\end{array}$ \\
\hline Controls & $12.1 \pm 2.9$ & $12.5 \pm 2.1$ & $11.2 \pm 2.0$ & $4.1 \pm 0.7$ & $3.9 \pm 0.6$ & $3.9 \pm 0.4$ & $1.26 \pm 0.23$ & $1.29 \pm 0.16$ & $1.28 \pm 0.22$ \\
\hline LTVV & $10.4 \pm 1.2$ & $10.7 \pm 0.6$ & $12.7 \pm 1.7$ & $4.0 \pm 0.7$ & $3.8 \pm 0.5$ & $3.5 \pm 0.7$ & $1.20 \pm 0.16$ & $1.38 \pm 0.14$ & $1.30 \pm 0.27$ \\
\hline DOSS & $11.2 \pm 3.6$ & $11.3 \pm 2.0$ & $12.5 \pm 2.0$ & $3.7 \pm 0.8$ & $4.1 \pm 0.7$ & $4.0 \pm 0.8$ & $1.25 \pm 0.22$ & $1.20 \pm 0.19$ & $1.28 \pm 0.27$ \\
\hline $\begin{array}{l}\text { DOSS+ } \\
\text { LTVV }\end{array}$ & $11.0 \pm 1.5$ & $8.4 \pm 1.2 * \ddagger$ & $9.5 \pm 2.1 *$ & $4.3 \pm 0.8$ & $4.7 \pm 0.8$ & $4.3 \pm 0.8$ & $1.18 \pm 0.09$ & $0.99 \pm 0.11^{\# *}$ & $1.06 \pm 0.13$ \\
\hline
\end{tabular}

Values are presented as mean \pm SD. LTVV: large tidal volume ventilation; $P_{\mathrm{a}, \mathrm{O}_{2}}$ : partial pressure of $\mathrm{O}_{2}$ in arterial blood; $P$ a, $\mathrm{CO}_{2}$ : partial pressure of $\mathrm{CO}_{2}$ in arterial blood; Cdyn: dynamic compliance; DOSS: dioctyl sodium sulphosuccinate (detergent). *: p $<0.05$,

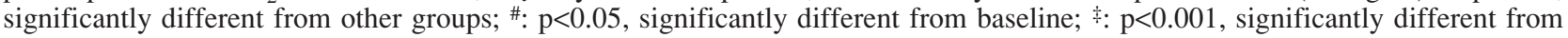
baseline.
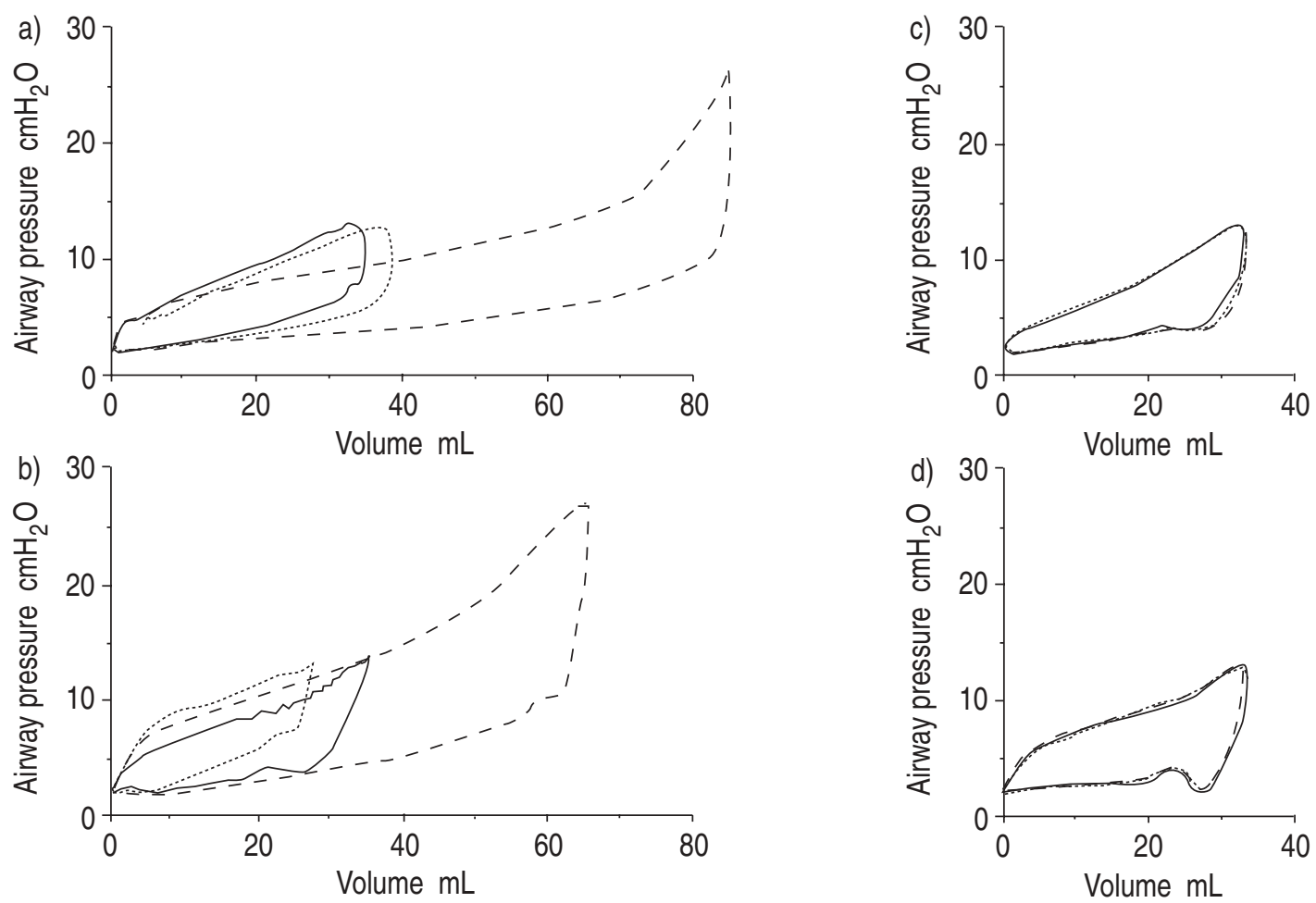

Fig. 2. - Representative pressure/volume curve from: a) LTVV group; b) Detergent+LTVV group; c) Control group; and d) Detergent group. The curves in each group are at: Baseline (_- $)$; Experimental ventilation $\left(---_{-}\right)$; and during Recovery (------). Loops are inscribed in a clockwise direction. 
Clearance of $99 m$ Tc-HSA during experimental ventilation

The pulmonary distribution of the tracer was uniform in the frontal projection in all animals. Clearance during Experimental ventilation was calculated over the first $90 \mathrm{~min}$ (table 2). Clearance in the Control and LTVV groups was adequately described by a monoexponential function. Clearance in the LTVV group was faster than in Controls. Unlike the Controls and the LTVV groups, a biexponential function was significantly better in describing the increased clearance in all of the six animals in the Detergent and Detergent+ LTVV groups $(\mathrm{p}<0.05$; F-test $)$. Clearance was also biexponential when $99 \mathrm{mTc}-\mathrm{HSA}$ was administered $60 \mathrm{~min}$ after Detergent (Protocol B). Comparing the results when $99 \mathrm{~m}$ Tc-HSA was given immediately (Protocol A) or $60 \mathrm{~min}$ after detergent according to previous principles [9] showed that $t 1 / 2 \mathrm{FS}$ was 170 min (range 140$210 \mathrm{~min}$ ). This value was used in further calculation according to Equation (3). The $t 1 / 2 \mathrm{~S}$ in the Detergent+ LTVV group was significantly faster than the $t 1 / 2 \mathrm{~S}$ in the Detergent group. $t 1 / 2 \mathrm{~F}$ and $\mathrm{fF}$ were statistically nondistinguishable in the Detergent and Detergent+LTVV groups. Normalized mean clearance curves from the different groups are shown in figure 3.

Clearance was biexponential when detergent was administered only once at $90 \mathrm{~min}$ (Protocol C) with $t 1 / 2 \mathrm{~F}$ 21.2 $\pm 9.9 \mathrm{~min}, t 1 / 2 \mathrm{~S} 870 \pm 91 \mathrm{~min}$ and a $\mathrm{fF}$ of $14.5 \pm 1.1$.

Clearance calculated over 30 min just before and after the second administration of Detergent in Protocol A did not result in an increased clearance $(t 1 / 2=554 \pm 219$ versus $629 \pm 147 \mathrm{~min})$, whereas it resulted in an increased clearance $(\mathrm{p}<0.01)$ in the Detergent+LTVV group (262 \pm 63.1 versus $192 \pm 67.6 \mathrm{~min})$.

\section{Clearance of ${ }^{99 m}$ Tc-HSA during the recovery period}

Over the 180 min Recovery period, clearance of 99mTcHSA was similar and adequately described by a monoexponential function in the Control and LTVV groups (table 3). Since both these groups displayed monocompartmental kinetics, no correction for residual activity from the first deposition was required. Clearance was

Table 2. - Half-life of clearance of $99 \mathrm{mTc}$-HSA during 90 min of Experimental ventilation $(n=6$ in each group)

\begin{tabular}{lcccc}
\hline & $\begin{array}{c}t 1 / 2 \\
\mathrm{~min}\end{array}$ & $\begin{array}{c}t 1 / 2 \mathrm{~S} \\
\mathrm{~min}\end{array}$ & $\begin{array}{c}t 1 / 2 \mathrm{~F} \\
\mathrm{~min}\end{array}$ & $\mathrm{fF}$ \\
\hline Controls & $1055 \pm 241$ & - & - & - \\
LTVV & $305 \pm 82.6^{\dagger}$ & - & - & - \\
Detergent & & $670 \pm 164^{+}$ & $15.4 \pm 4.4$ & $0.20 \pm 0.09$ \\
Detergent+LTVV & $313 \pm 81.2^{\ddagger}$ & $13.8 \pm 3.3$ & $0.21 \pm 0.08$
\end{tabular}

Values are presented as mean \pm SD. ${ }^{99 m}$ Tc-HSA: technetium99m-labelled human serum albumin; LTVV: large tidal volume ventilation; $t 1 / 2$ : monoexponential half-life; $t 1 / 2 \mathrm{~F}$ : half-life of clearance from the fast compartment; $t 1 / 2 \mathrm{~S}$ : halflife of clearance from the slow compartment; fF: fraction of radiotracer cleared by the fast compartment. ${ }^{+}: \mathrm{p}<0.01$, significantly different from $t 1 / 2$ in Controls; ${ }^{\dagger}: \mathrm{p}<0.001$, significan-

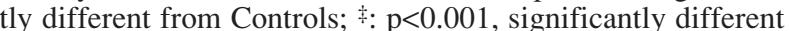
from the Detergent group.
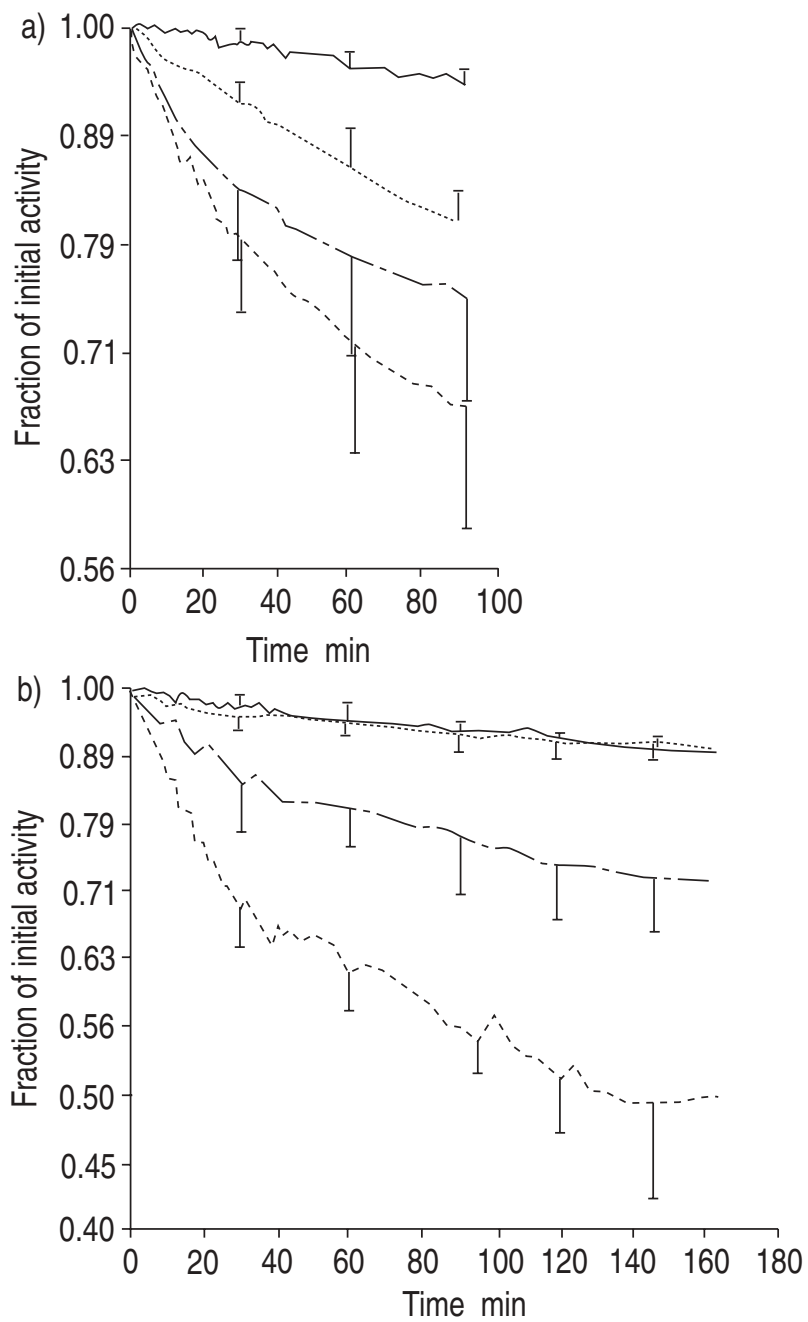

Fig. 3. - Normalized clearance curves from each group during: a) Experimental ventilation; and b) Recovery period, plotted on a semilogarithmic scale. Values are presented as mean \pm SD. - : Control; ----- : LTVV; LTVV: Large tidal volume ventilation; DOSS: dioctyl sodium sulphosuccinate (detergent).

significantly slower $(\mathrm{p}<0.001)$ than that calculated over $3 \mathrm{~h}$ of Experimental ventilation in the LTVV group $(366 \pm 25.2 \mathrm{~min})$. A biexponential fit adequately described the clearance in the Detergent and Detergent+LTVV groups during the Recovery period. Accordingly, in these two groups the time activity curve from the Experimental period was extrapolated into the Recovery period to correct for the residual activity from the first

Table 3. - Half-life of clearance of 99m-Tc-HSA during 180 min of Recovery ( $n=6$ in each group)

\begin{tabular}{lcccc}
\hline & $\begin{array}{c}t 1 / 2 \\
\mathrm{~min}\end{array}$ & $\begin{array}{c}t 1 / 2 \mathrm{~S} \\
\mathrm{~min}\end{array}$ & $\begin{array}{c}t 1 / 2 \mathrm{~F} \\
\mathrm{~min}\end{array}$ & $\mathrm{fF}$ \\
\hline Controls & $1081 \pm 251$ & - & - & - \\
LTVV & $1268 \pm 207$ & - & - & - \\
Detergent & & $657 \pm 181^{\dagger}$ & $18.7 \pm 6.2$ & $0.17 \pm 0.09$ \\
Detergent+LTVV & $318 \pm 63.3^{\ddagger+}$ & $13.3 \pm 3.8$ & $0.36 \pm 0.05^{+}$ \\
\hline
\end{tabular}

Values are presented as mean \pm SD. ${ }^{+}: \mathrm{p}<0.01$, significantly different from Detergent group; $\dagger: \mathrm{p}<0.01$, significantly different from $t 1 / 2$ in Controls; $: \mathrm{p}<0.001$, significantly different from $t 1 / 2$ in the LTVV group. 
deposition to calculate $\mathrm{fF}$. In the Detergent group, $t 1 / 2 \mathrm{~S}$ was faster than the monoexponential clearance in the Control group. Clearance in the Detergent+LTVV group was characterized by a $t 1 / 2 \mathrm{~S}$ that was persistently faster than both the $t 1 / 2 \mathrm{~S}$ of the Detergent group and the monoexponential $t 1 / 2$ of either the Control or LTVV group. This group also had a significantly larger fF compared to the period of Experimental ventilation $(p<0.05)$ and compared to the Detergent group.

\section{Discussion}

Alveolocapillary permeability has been extensively studied by pulmonary clearance of $99 \mathrm{mTc}-\mathrm{DTPA}$. Alveolocapillary transfer of large molecules, such as $99 \mathrm{mTc}-$ HSA, is much slower in healthy lungs than the transport of smaller molecules, such as $99 \mathrm{mTc}$-DTPA. A common interpretation is that two populations of pores exist in the alveolocapillary membrane. The transport of albumin is thought to be restricted to pores with a large diameter. The anatomical correlate to such pores has not been established. Tight junctions may be the anatomical site for pores. It has been speculated that adsorbed phospholipid molecules might restrict the diffusion of solutes through the pores [2]. We have shown that the surfactant system plays an important roll in limiting the alveolocapillary permeability of 99mTc-DTPA [9, 16]. The mechanisms are not known. In the present study, the clearance kinetics of the larger molecule, $99 \mathrm{mTc}-\mathrm{HSA}$, was evaluated after detergent administration and during LTVV, in order to give further insight into mechanisms governing the alveolocapillary transfer of solutes.

Detergent led to an accelerated and biexponential clearance of $99 \mathrm{~m} \mathrm{Tc}-\mathrm{HSA}$, which in principle is similar to its effect on clearance of 99mTc-DTPA [9]. We ruled out any chemical effect of detergent on the radiotracer as an explanation of our findings. The results when detergent was given only once at 90 min were similar to when detergent was given immediately after ${ }^{99 \mathrm{~m} T c-H S A}$. This implied that any change in the albumin pool which would restrict its clearance, such as uptake by macrophages, is unlikely over the time course of this study. The biexponential clearance could, according to principles of kinetics, reflect either a transient effect of detergent or the induction of a pool of radiotracer that clears with a short time constant [9].

We determined that the effect of detergent on clearance of $99 \mathrm{~m}$ Tc-HSA was halved in $170 \mathrm{~min}$, which is similar to that observed with $99 \mathrm{mTc}-\mathrm{DTPA}$ [9]. Our results were calculated on the basis of this duration of the detergent effect, and it was found that the calculation would be significantly affected only if this half-life were shorter than $60 \mathrm{~min}$. Reasonable errors in the estimation of $t 1 / 2 \mathrm{FS}$ would, therefore, be of no importance. Hence, we conclude that the biexponential clearance with detergent reflects the induction of two pools of radiotracer. The two pools do not exchange the tracer freely, otherwise the resulting clearance would still be described by a monoexponential function [9].

A second dose of detergent was given 90 min after the first one in order to illustrate the nature of the two compartments. The second dose did not increase the clearance in the detergent group. At that time, the fast compartment with a $t 1 / 2$ of 15 min would contain less than $2 \%$ of its initial activity. The effect of detergent on clearance from that compartment would, therefore, be trivial. The slow pool, which at the same moment would contain more than $94 \%$ of its tracer, was found not to react to the second dose. The fact that the slower compartment did not become fast suggests that the fast and the slow compartments represent areas within the lung with different properties throughout the experiment. This study does not indicate whether the compartments represent longitudinal differences along the airways down to the peripheral alveoli, or whether they represent different alveoli, or even different areas within a single alveolus.

In a previous study on the effects of detergent on the pulmonary clearance of 99mTc-DTPA [9], we speculated that detergent might cause alveolar instability, with reduction in alveolar volume in some regions and hyperinflation in others. Such a bimodal distribution of alveolar volume could explain a biexponential clearance of the tracer from the lungs. In this study, more detailed studies of lung mechanics were performed showing no differences between the groups given vehicle and detergent. In particular, $\mathrm{P} / \mathrm{V}$ loops are suitable to show alveolar instabilities. The unchanged mechanical properties and gas exchange after detergent suggest that alveolar instability and uneven distribution of alveolar volume are not the reason for two compartments. Thus, other mechanisms must be considered. Furthermore, unaltered compliance suggests that the small dose of detergent does not significantly increase surface tension in the alveoli.

The small dose of detergent supported by unchanged compliance and gas exchange, and normal morphology (unpublished results), suggests that altered permeability is consistent with the previously observed effect of detergents on alveolar surfactant $[9,16,19,20]$. Detergent administered under identical circumstances, induced a fast compartment of 99mTc-DTPA which comprised $80 \%$ of the tracer pool [9], compared to $20 \%$ for ${ }^{99 m}$ TcHSA in the present study. The nebulization technique and the gamma camera images over the thorax showing peripheral distribution were similar in both studies, and yet there was a fourfold difference in the fast fraction of the two tracers. The increase in the clearance rate of the fast compartment of $99 \mathrm{mTc}-\mathrm{HSA}$ was 50 fold. The same relative increase has been reported for 99mTc-DTPA [9]. The detergent is a wetting agent with a wedge-shaped molecular configuration that is liable to interfere with surfactant complexes. Surfactant, or at least osmiophilic, substances are known to be associated with tight junctions in epithelial and endothelial membranes, such as gastric mucosa, the eustachian tube and cerebral microvasculature. We are not aware of any study on this aspect of the alveolar membrane. If phospholipids are also associated with tight junctions in the alveoli, detergent might interact with the surfactant to change the properties of the tight junction. Such an interaction might modulate both number and size of pores and, thereby, lead to complex patterns of permeability for large and small molecules. Another explanation is that the surfactant film is directly adsorbed to the epithelium. Wetting of dry surfaces might then expose a larger 
number of pores for diffusion of water soluble substances. Such a phenomenon could explain the existence of nonmixing pools of tracers.

It is well-established that lung inflation by PEEP enhances clearance of $99 \mathrm{mTc}-\mathrm{HSA}[11,12]$. The increased clearance has been attributed to a change in pore size [13], which may occur in hyperdistended alveoli. Hyperdistention in this study may be indicated by the almost zero compliance found in the terminal portion of the $\mathrm{P} / \mathrm{V}$ curve (fig. 2). Clearance of $99 \mathrm{mTc}-\mathrm{HSA}$ followed a monoexponential course during LTVV and was threefold faster than during conventional ventilation. A faster than normal monoexponential clearance of $99 \mathrm{~m}$ Tc-DTPA was also seen during LTVV $[14,16]$. The qualitative effect of PEEP is similar $[12,15]$. The monoexponential feature can be attributed to a uniform and global effect on the clearance of the entire radiotracer pool in the lung, and may well support increased pore size.

The increased clearance reverted completely after cessation of LTVV. Clearance during the Recovery period was slower in the LTVV group than in Controls. Although not significant, this tendency may be related to an increased release of surfactant, which is known to occur at large inflations of the lungs [21]. The observation that dynamic compliance was increased after the LTVV period may support that notion. The latter observation is a further indication that LTVV, as applied in this study, is not deleterious to the lung.

Considering that the barrier is differently affected by detergent and LTVV, the kinetics of clearance in the Detergent+LTVV group indicates an additive nature of the mechanisms of detergent and LTVV on barrier function. In the present study, the conditions were regulated so that LTVV or detergent would, by itself, produce almost no change in lung mechanics or gas exchange, allowing adequate scope for the delineation of their combined effect. In the combination group, we found reduced compliance and impaired gas exchange as evidence of lung damage, further emphasizing that the two interventions produce additive effects. The additive effects of detergent and LTVV may have profound implications in the clinical setting, since surfactant perturbation may be present in adult respiratory distress syndrome (ARDS), and utilizing normal to high tidal volumes to achieve adequate oxygenation would increase the propensity for lung damage.

During Recovery, clearance in the Detergent+LTVV group did not revert, unlike clearance in the Detergent and LTVV groups. The fF was even higher during Recovery compared to the period of Experimental ventilation and as compared to the Detergent group. The extrapolation of the time activity curve from Experimental ventilation into the Recovery period was performed to avoid underestimation of $\mathrm{fF}$ due to residual radioactivity in the slow compartment from the first deposition. This may be associated with a potential error mainly in the Detergent+LTVV group, as the return to conventional ventilation during Recovery might reduce the clearance rate of albumin from the slow pool, as was observed in the LTVV group. The error would lead to an underestimation of the clearance rate and fF during the Recovery period. Our basic contention of an increased fF would, thus, be relevant. Since the values of $t 1 / 2 \mathrm{~S}$ in this group during Experimental ventilation and Recovery have been close, we would expect no major error due to extrapolation.

$\mathrm{Pa}_{\mathrm{a}} \mathrm{O}_{2}$ and compliance remained low in the Detergent+ LTVV group. The P/V curve during Recovery (fig. 2) showed a considerable increase in the pressure that was required to produce volume change at the beginning of inspiration. These features together suggest a lung that partially collapses during expiration because of surfactant deficiency or inactivation. Plasma proteins, including albumin, are known to inactivate alveolar surfactant [22]. Since albumin leaks from the alveoli to the blood and more so in the Detergent+LTVV group, it is natural that proteins may diffuse in the other direction. It needs to be emphasized that the albumin delivered to the lungs in the form of $99 \mathrm{mTc}$-HSA is in trace amounts that do not have any significant biological effect.

The lungs are obviously damaged by the combination of detergent and LTVV. The damage is evident already during the latter half of Experimental ventilation, when a second dose of detergent was administered and clearance was further accelerated. This is despite the fact that the fast compartment with a $t 1 / 2$ of only $12 \mathrm{~min}$ should be nearly free of tracer at that time, and is in contrast to the findings when a second dose of detergent was administered in the group with conventional ventilation. The finding implies that the damage has extended into areas previously not affected by detergent. This is further supported by the finding of an increase in the fF during Recovery. Lung damage was also presented postmortem as foam in the airway and oedema on the cut lung surface.

In conclusion, the mechanisms of an increase in clearance during lung distension related to large tidal volume ventilation and perturbation of the surfactant system with detergent are different, as seen from the distinct nature of their clearance kinetics. When these mechanisms are combined, they display additive features. Either of the individual mechanisms related to detergent or large tidal volume ventilation is reversible. However, a combination of detergent and large tidal volume ventilation leads to nonreversible changes in lung function and lung injury.

\section{References}

1. Matthay MA, Wiener-Kronish JP. Intact epithelial barrier function is critical for the resolution of alveolar edema in humans. Am Rev Respir Dis 1990; 142: 12501257.

2. Effros RM. Permeability of the blood-gas barrier. In: Crystal RG, West JB, Barnes PJ, Cherniack NS, Weibel ER, eds. The Lung: Scientific Foundations. New York, Raven Press, 1991; pp. 1163-1176.

3. Kim K-J, Crandall ED. Heteropore populations of bullfrog alveolar epithelium. $J$ Appl Physiol: Respirat Environ Exercise Physiol 1983; 54: 140-146.

4. Wollmer P. Transfer of $99 \mathrm{~m}$ Tc-DTPA, lung surfactant and lung injury: a review of the literature. Appl Cardiopulm Pathophysiol 1991; 4: 155-160.

5. Wollmer P, Jonson B, Lachmann B. Evaluation of lung permeability in neonatal RDS and ARDS. In: Lenfant C, ed. Surfactant Therapy For Lung Disease. Lung Biology in Health and Disease Series. New York, Dekker, 1995; pp. 199-213. 
6. Jefferies AL, Dunn MS, Possmayer F, Tai KFY. ${ }^{99 m T c-}$ DTPA clearance in preterm lambs. Effect of surfactant therapy and ventilation. Am Rev Respir Dis 1993; 148: 845-851

7. Evander E, Wollmer P, Jonson B, Lachmann B. Pulmonary clearance of inhaled $99 \mathrm{mTc}$-DTPA: effects of surfactant depletion by lung lavage. J Appl Physiol 1987; 62: 1611-1614.

8. Nieman G, Ritter-Hrncirik C, Grossman Z, Witanowski L, Clark W Jr, Bredenberg C. High alveolar surface tension increases clearance of technetium $99 \mathrm{~m}$-diethylenetriamine penta-acetic acid. J Thorac Cardiovasc Surg 1990; 100: 129-133.

9. Evander E, Wollmer P, Valind S, Sörnmo L, John J, Jonson B. Biexponential pulmonary clearance of $99 \mathrm{mTc}$ DTPA induced by detergent aerosol. J Appl Physiol 1994; 77: 190-196.

10. Bos JAH, Wollmer P, Bakker W, Hannappel E, Lachmann B. Clearance of 99mTc-DTPA and experimentally increased alveolar surfactant content. J Appl Physiol 1992: 72; 1413-1417.

11. Barrowcliffe MP, Zanelli GD, Jones JG. Pulmonary clearance of radiotracers after positive end-expiratory pressure or acute lung injury. $J$ Appl Physiol 1989; 66: 288-294.

12. Peterson BT, Dickerson KD, James HL, Miller EJ, McLarty JW, Holiday DB. Comparison of three tracers for detecting lung epithelial injury in anesthetized sheep. J Appl Physiol 1989; 66: 2374-2383.

13. Marks JD, Luce JM, Lazar NM, Wu N-S, Lipavsky A, Murray JF. Effect of increases in lung volume on clear- ance of aerosolized solute from human lungs. $J$ Appl Physiol 1985; 59: 1242-1248.

14. Evander E, Wollmer P, Jonson B. Pulmonary clearance of inhaled 99mTc-DTPA: effects of ventilation pattern. Clin Physiol 1990; 10: 199-209.

15. Peterson BT, James HL, McLarty JW. Effects of lung volume on clearance of solutes from the air spaces of lungs. J Appl Physiol 1988; 64: 1068-1075.

16. Taskar V, Wollmer P, Evander E, John J, Jonson J. Effect of detergent combined with large tidal volume ventilation on alveolocapillary permeability. Clin Physiol 1996; 16: 103-114.

17. Barrowcliffe MP, Otto C, Jones JG. Pulmonary clearance of 99mTc-DTPA: influence of background activity. J Appl Physiol 1988: 64; 1045-1049.

18. Nelder JA, Mead R. A simplex method for function minimization. Comput J 1965; 7: 308-313.

19. Nilsson K, Wollmer P. Pulmonary clearance of 99mTcDTPA and $99 \mathrm{mTc}$-albumin in rabbits with surfactant dysfunction and lung injury. Clin Physiol 1992; 12: 587-594.

20. Nieman GF, Bredenberg CE. High surface tension pulmonary edema induced by detergent aerosol. $J$ Appl Physiol 1985; 58: 129-136.

21. Massaro GD, Massaro D. Morphologic evidence that large inflations of the lung stimulate secretion of surfactant. Am Rev Respir Dis 1983; 127: 235-236.

22. Seeger W, Grube C, Gunther A, Schmidt R. Surfactant inhibition by plasma proteins: differential sensitivity of various surfactant preparations. Eur Respir J 1993; 6: 971-977. 